\title{
Paraganglioma of the Filum Terminale
}

\author{
RÉAL LAGACÉ, CLAUDE DELAGE AND FRANÇOIS GAGNÉ
}

SUMMARY: An unusual tumor arising in the filum terminale is described. The clinical data revealed an extensive and slowly growing lesion. The histologic picture was characterized by a proliferation of lobules and sheets of regular cells within a rich vascular network. Electron microscopic studies showed light and dark cells with sustentacular extensions. Typical nearosecretory granules were observed in both cell types, establishing the diagnosis of para-ganglioma. The glomas coccygeam could be the site of this tumor.

RÉSUMÉ: Un cas d'une tumear inhabituelle originant dans le filum terminale est décrit. Cliniquement, il s'agit d'une lésion extensive et lentement évolutive. La tumeur se caractérise histologiquement par une prolifération de lobules et de cordons cellulaires séparés par un réseau vasculaire bien développé. L'étude ultra-structurale montre la présence de cellules claires et foncées ayant des extensions sustentaculaires. La mise en évidence de granules neurosécrétoires typiques confirme un diagnostic de paragangliome.
From the Department of Pathology, Laval University, Quebec City, (Quebec), Canada.

Reprint requests to: Dr. Réal Legacé, Department of Pathology, L'Hotel-Dieu de Quebec, 11, Cote du Palais, Quebec, Quebec, Canada GIR $2 J 6$.

\section{INTRODUCTION}

Paragangliomas arising below the diaphragm are rare. They have been reported at the site of aortico-sympathetic paraganglia, commonly in the retro-peritoneal space (Olson and Abell, 1969) and in the organ of Zuckerkandl (Attia, Golden and Ziffer, 1961). They have also been observed within the visceral-autonomic paraganglia particularly the kidney (Cohen and Persky, 1966), the urinary bladder (Leetsma and Price, 1971) and the duodenum (Taylor and Helwig, 1962; Kepes and Zacharias, 1971). These tumors, especially those with morphologic variants, are difficult to classify. A few reports of paragangliomas of the filum terminale have appeared in the literature (Miller and Thorack, 1970; Lerman, Kaplan and Daman, 1972; Horoupion, Kerson, Saiontz et al., 1974).

This paper presents the clinicopathologic and the light and electron microscopic findings of a paraganglioma of the filum terminale, with particular reference to its histogenesis.

\section{CASE REPORT}

The patient, a 55 year old man, had a three year history of low-back pain exaggerated by walking and sitting. Three weeks before admission, he noted an increasing pressure in his left thigh. Examination revealed rigidity of the lumbo-sacral spine and weakness of the left quadriceps. No sensory deficit was noted, but the patellar and achilles tendon reflexes were decreased. X-rays of the lumbo-sacral spine showed an extensive lesion involving the superior area of the sacral spine and extending to L5. Destruction of the posterior wall of the vertebral bodies was noted. These findings were confirmed by tomograms and the tumor measured about $10 \times 5.5 \mathrm{~cm}$. A myelogram from below showed a complete block at L4, but a normal opacification of the intramedullary channel to the occipital hole. The radiological diagnosis was a slowly growing tumor such as a lipoma or neurofibroma.

Laminectomies of the fourth and fifth lumbar vertebral and the first part of the sacrum disclosed a vascular tumor protruding between LS and S1. The arachnoid and the dura could not be identified. Incomplete surgical resection was performed. The postoperative course was uneventful. Twenty six months later, the patient was doing well and there were no sensory or motor deficits.

\section{PATHOLOGY \\ Gross appearance}

The resected specimen consisted of 35 grams of fragmented soft, spongy, reddish tissue with grayishbrown areas, showing hemorrhagic foci, and measuring from 0.5 to 2.5 $\mathrm{cm}$ in their greatest diameter.

\section{Light microscopy}

No distinct capsule could be seen. The fragments showed an organ-like and glandular pattern. Clusters or sheets of polyhedral or polygonal cells were interspersed within a rich vascular network (Figure 1). The cells were large with ill-defined margins and moderate eosinophilic cytoplasm. The nuclei were large, regular, rounded or oval, with faint chomatin and one or two small nucleoli. Mitotic figures were absent. In some areas, the cells were spindleshaped, forming fascicles and pseudo-rosettes around blood vessels, suggestive of an ependymal nature (Figure 2). Laidlaw's stain for reticulin underlined the endocrine pattern of the tumor with a clear delineation of the vascular framework. 


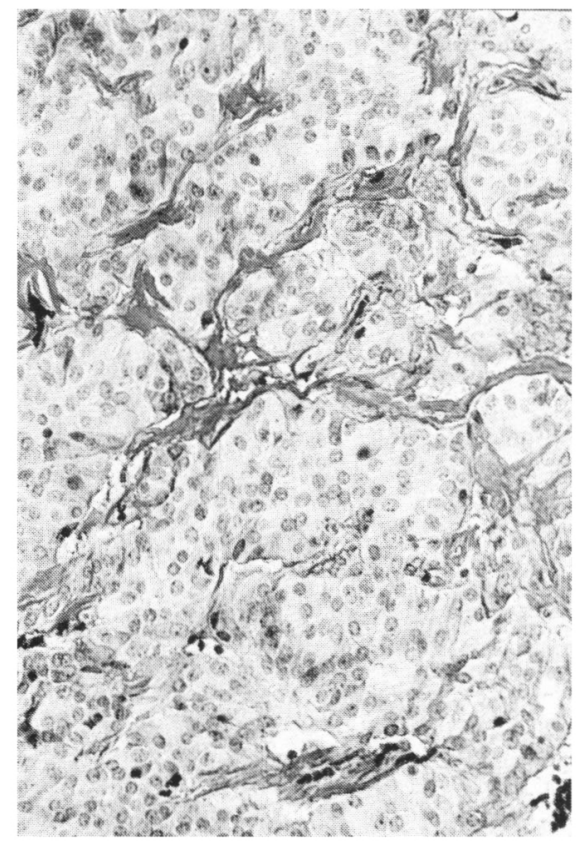

Figure 1-Groups of tightly packed polygonal cells separated by numerous vessels (Hematoxylin and Eosin, $\times 260$ ).
Gomori's reaction for chromaffin tissue, phosphotungstic acid hematoxylin stain for glial fibrils, periodic acid Schiff with and without diastase digestion, and Alcian blue stain for mucopolysaccharides gave negative results.

\section{Electron microscopy}

Electron microscopic studies revealed two predominent cell types, light and dark, closely juxtaposed and sometimes separated by interdigitations.

The dark cells were uniform in shape. Sometimes polygonal, they also showed sustentacular cytoplasmic extensions, readily seen in cross section (Figure 3). They had irregular, often indented nuclei with clumpy chromatin coarsely condensed along the nuclear membrane. About half of these cells had a nucleolus. The cytoplasm was crowded with numerous, mostly spheric mitochondria, profiles of rough endoplasmic reticulum, and prominent

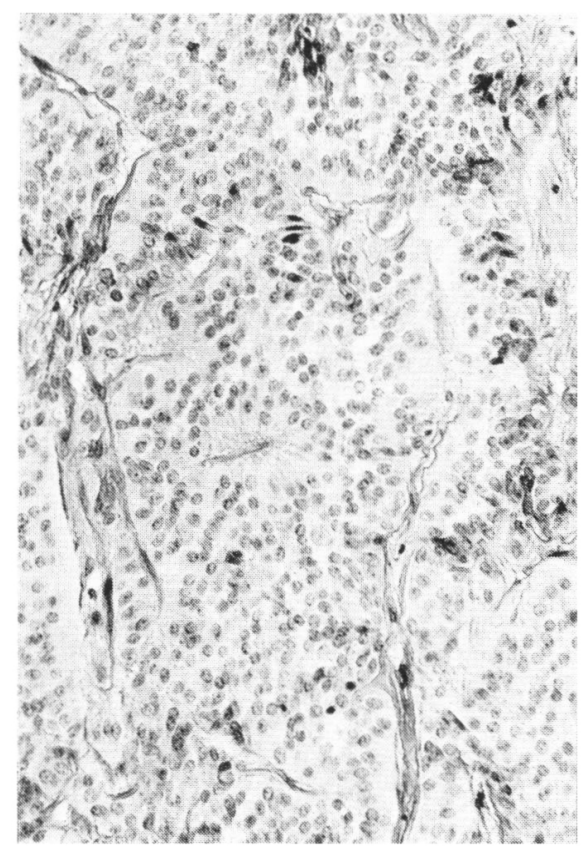

Figure 2-Another field of the tumor, showing cells oriented toward blood vessels (in the center), suggestive of pseudo-rosettes (Hematoxylin and Eosin, X 180).

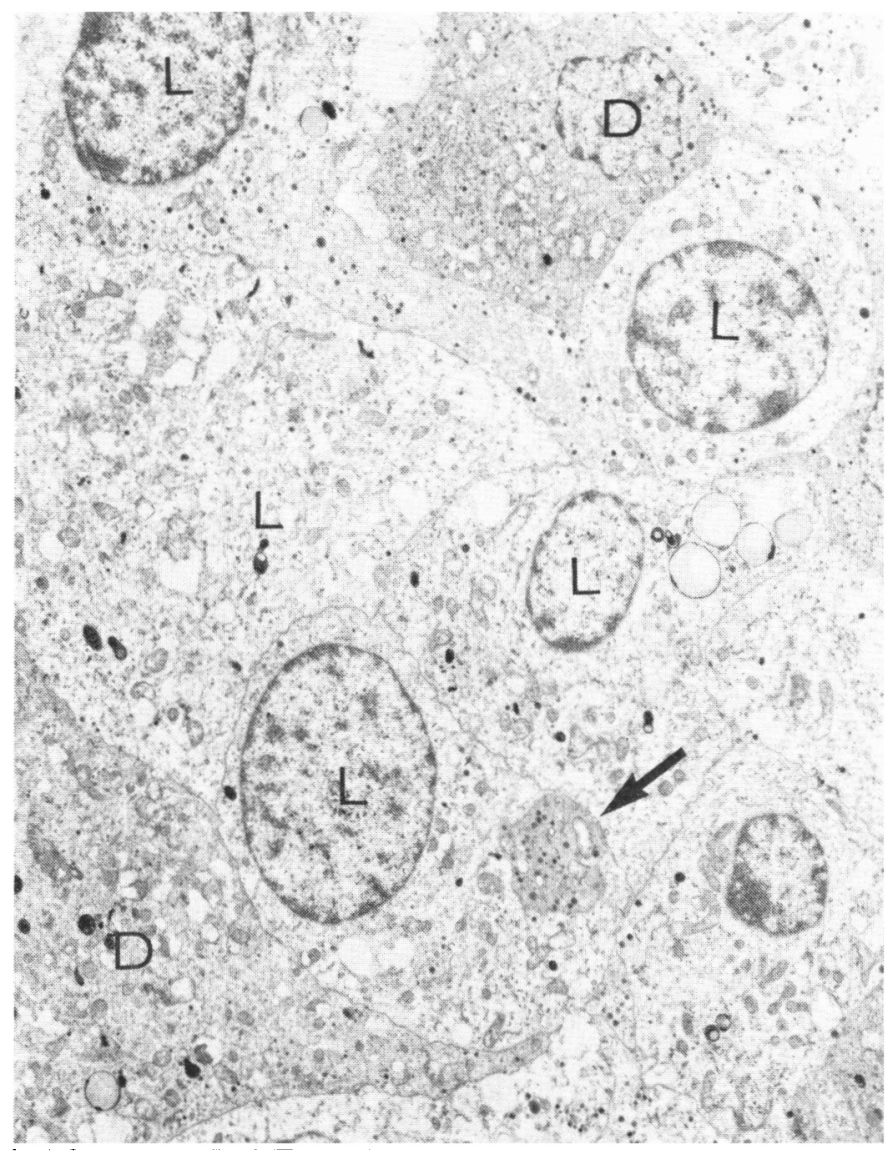

Figure 3-Electron micrograph showing light cells (L) and dark cells (D), with a sustentacular cy toplasmic extension (arrow) $\mathrm{X}$ 4,700 .

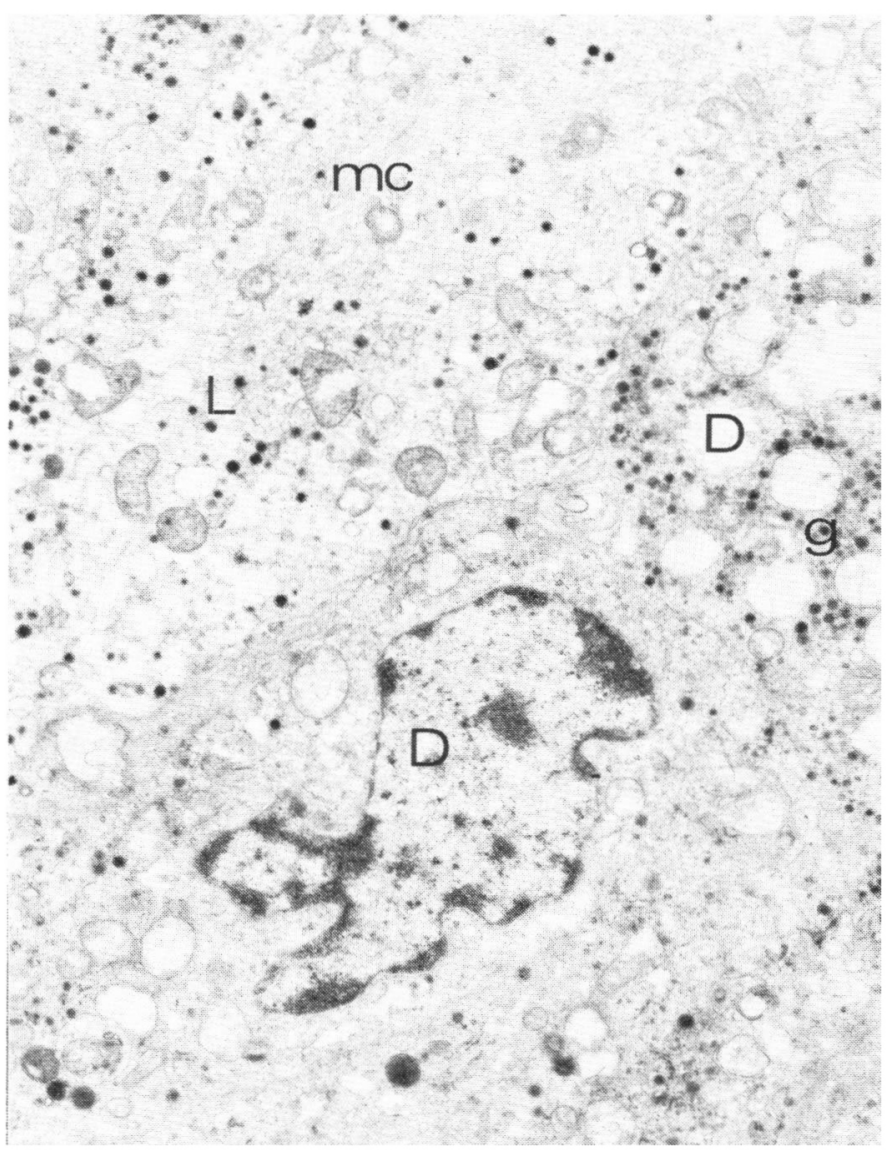

Figure 4-Electron micrograph of a light cell (L) and two dark cells (D), containing numerous membrane-bound dense granules $(\mathrm{g})$. Note the micro-fibrillary network (mc). $\times 9.400$. 
Golgi complexes. Dense bodies of lysosomial-type were also observed. The striking morphologic feature was the presence, in variable amounts, of dense neurosecretory granules. Their dense central cores were usually separated from the limiting membrane by a clear halo (Figure 4). Most of the granules were uniform in size, averaging $35-\AA$ in diameter. $A$ delicate microfibrillary network was present throughout the cell cytoplasm. These cells lacked a basal lamina, but sometimes a basementmembrane like material was observed in the areas where the tumor cells were in close contact with the capillaries.

The clear cells were also uniform in shape and in size. They were usually smaller than their dark counterpart, round and oval, and exhibited a round and regular nucleus (Figure 4). Nucleoli were rarely seen and the chromatin was either finely granular and dispersed in the nucleoplasm or clumped along the nuclear membrane. Identical cy toplasmic organelles were observed. Rare lipidic vacuoles could be seen in these cells. Free ribosomes and poly-ribosomes were distributed throughout the cytoplasm.

Both dark and clear cells showed occasional desmosome-like junctional complexes. The tumor cells were usually separated from the vascular component either by pericytelike cells or by a multilamellated basal lamina surrounding the capillaries (Figure 5). Pericytes were recognized by their micropinocy totic activity, a rich fibrillary network with minute osmiophilic condensations, a well developed, rough endoplasmic reticulum and a distinct basement membrane.

Blood vessels were not uniform in size. Sometimes small capillaries showed a lumen with a unique hyperplastic endothelial cell. Vessels of greater size were characterized by numerous hyperplastic endothelial cells whose cytoplasm contained numerous dense bodies of lysosomial-type and dense granules similar to the neurosecretory granules. They also showed micropinocy totic activity.

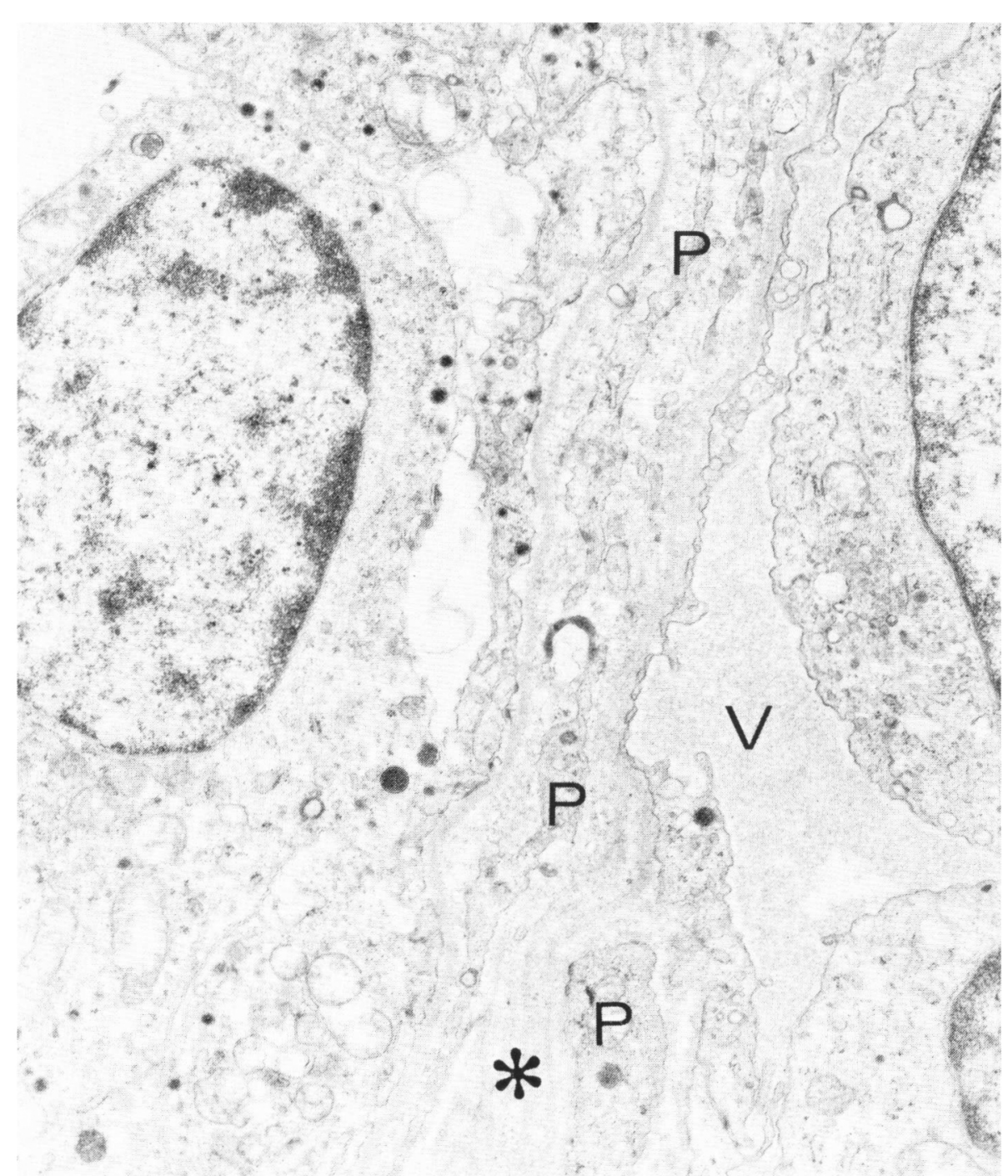

Figure 5-Close association of the tumor cells with a vessel (V). The cells and the vessels are separated by pericytes extensions $(P)$. The endothelial cells are in contact with a multilayered basal lamina $(*) . X 9,400$.

\section{DISCUSSION}

In contrast to the previously published cases of paragangliomas arising in the filum terminale, the histopathologic picture in the present report is quite typical. The identification of osmiophilic neurosecretory granules with the electron microscope further supports the diagnosis. The case reported by Miller and Thorack.(1970) was considered to be a secretory ependymoma of the filum terminale. We agree with Horoupion et al. (1974) that secretory ependymoma is a misnomer since the morphologic criteria of the tumor are questionable. The typical neurosecretory granules have not been observed in the cytoplasm of epen- dymal cells in animals or in humans. Moreover, ultra-structural findings such as cilia, junctional complexes, and microvilli, which Miller and Thorack (1970) considered as characteristic of ependymomas, may be observed in other tumors (Goebel and Craviatro, 1972). We think Miller and Thorack's case could be a paraganglioma rather than an ependymoma. Lerman et al. (1972) have also reported an unusual neoplasm of the filum terminale, showing areas of neuroblastic and paraganglionic differentiation. They proposed the term ganglioneuroma or paraganglioma of the intradural filum terminale. The case reported by Horoupion et al. (1974) has histologic features similar 
to ours. The ultrastructural findings are in agreement with the previous studies of tumors originating in the paraganglionic system (Glenner and Grimley, 1974). The association of dark and light cells, the interdigitating extensions (sustentacular projections), and the presence of clusters of neuro-secretory granules have been well described and constitute features that were present in our case.

The tumor from our patient regressed following combined treatment of 6,000 Rads of cobaltherapy and electron therapy. Reported data on the radiotherapy of paraganglioma are not well documented. Gaylis et al. (1966) reported relatively successful radiotherapy in a case of a retroperitoneal paraganglioma. The patient received cobaltherapy and was alive and reasonably well a year after the treatment. However, no mention of radiation doses was given.

Although paragangliomas of the filum terminale are rare, the localization is not surprising since the paraganglionic cells share a common origin with the neural crest. During embryogenesis, there is a migration of these cells along the neural tube. Therefore, these cells, on the basis of their morphologic and biologic features, are related to other cellular components of the APUD series (Pearse, 1969). Moreover, the demonstration of a so-called "glomuscoccygeum" (Hollinshead, 1942) which is a collection of arteriovenous anastomoses, close to the tip of the coccyx, near the middle sacral artery, enhances the possibility that paragangliomas could arise in the area of the filum terminale.

\section{REFERENCES}

ATTIA, A., GOLDEN, R. L. and ZIFFER, H. (1961). Non-chromaffin-staining functional tumor of the organs of Zuckerkandl. N. Engl. J. Med. 264: 1130-1133.

COHEN, S. M. and PERSKY, L. (1966). Malignant non-chromaffin paraganglioma with metastasis to the kidney. J. Urol. 96: 122-126, 1966.

GAYLIS, H., ISAACSON, C. and SNEIDER, P. (1966). Retroperitoneal chemodectoma. Brit. J. Radiol. 39: 627-629. GLENNER, G. G. and GRIMLEY, P. M. (1974). Tumors of the extra-adrenal paraganglion system (including chemoreceptors). Atlas of Tumor Pathology, second series, fasc. 9, Washington, D.C., Armed Forces Institute of Pathology. GOEBEL, H. H. and CRAVIATRO, H. (1972). Ultrastructure of human and experimental ependymomas. A comparative study. J. Neuropathol. Exp. Neurol. 31: 54-71.
HOLLINSHEAD, W. H. (1942). A comparative study of the glomus coccygeum and the carotid body. Anat. Rec. 84: 1-16.

HOROUPION, D. S., KERSON, L. A. SAIONTZ, H. et al. (1974). Paraganglioma of cauda equina. Clinicopathologic and ultrastructural studies of an unusual case. Cancer 33: 1337-1348.

KEPES, J. J. and ZACHARIAS, D. L. (1971). Gangliocytic paraganglioma of the duodenum. A report of 2 cases with light and electron microscopic examination. Cancer 27: 61-70.

LEESTMA, J. E. and PRICE, E. B. Jr. (1971). Paraganglioma of the urinary bladder. Cancer 28: 1063-1073.

LERMAN, R. I., KAPLAN, E. S. and DAMAN, L. (1972). Ganglio-neuromaparaganglioma of the intradural filum terminale. J. Neurosurg. 36: 652-658.

MILLER, C. A. and THORACK, R. M. (1970). Secretory ependymoma of the filum terminale. Acta Neuropath. (Berlin) 15: 240-250.

OLSON, J. R. and ABELL, M. R. (1969). Nonfunctional, nonchromaffin paragangliomas of the retroperitoneum. Cancer 23: 1358-1367.

PEARSE, A. G. E. (1969). The cytochemistry and ultrastructure of polypeptide hormone-producing cells of the APUD series and the embryologic, physiologic and pathologic implications of the concept. J. Histochem. Cytochem. 17: 303-313.

TAYLOR, H. B. and HELWIG, E. B. (1962). Benign non-chromaffin paragangliomas of the duodenum. Virchows Arch (Pathol. Anat.) 335: 356-366. 